\title{
CHARACTERIZATION OF SECONDARY CARBIDE IN MARTENSITIC STAINLESS STEEL AFTER DEEP-CRYOGENIC TREATMENT PROCESSES
}

\author{
Kaweewat WORASAEN ${ }^{1}$, Suttipong WANNAPAIBOON ${ }^{2}$, Karuna TUCHINDA ${ }^{1}$, \\ Piyada SUWANPINIJ ${ }^{1}$
}

${ }^{1}$ The Sirindhorn International Thai-German Graduate School of Engineering (TGGS), King Mongkut's University of Technology North Bangkok (KMUTNB), Bangkok, Thailand

${ }^{2}$ Synchrotron Light Research Institute (SLRI), Nakhon Ratchasima, Thailand

kaweewat.w-mpe2016@tggs.kmutnb.ac.th

https://doi.org/10.37904/metal.2019.715

\section{Abstract}

The carbide in X90CrMoV18 martensitic stainless steel governs both hardness and fracture toughness, which are the key performance of tool steels. Optimizing these opposite properties results in longer tool life by increasing the wear resistance. Deep-Cryogenic Treatment (DCT) has been introduced in this research to fully transform the Retained Austenite (RA) into martensite and/or secondary carbide. The precipitation of $M_{7} C_{3}$ (Primary Carbide; $\mathrm{PC}$ ) increases only the hardness while $\mathrm{M}_{23} \mathrm{C}_{6}$ (Secondary Carbide; $\mathrm{SC}$ ) improves the toughness. Hence, the increase in $\mathrm{M}_{23} \mathrm{C}_{6} / \mathrm{M}_{7} \mathrm{C}_{3}$ carbide ratio will enhance the tool life and the role of DCT in this regard is our research focus. The carbide type, size and shape are observed by Scanning Electron Microscopy (SEM) and Light Optical Microscopy (LOM). The synchrotron Grazing Incident X-Ray Diffraction (GIXRD) is applied for investigating the change in c/a ratio of martensite matrix and carbide identification. The synchrotron X-ray Absorption Spectroscopy (XAS) is applied to the quantification of precipitation. The latter is quantified by XAS with Linear Combination Fit (LCF) of the Extended X-ray Absorption Fine Structure (EXAFS) spectra. A suitable DCT condition increases $4.2 \%$ in the hardness while surface toughness is raised to $150 \%$. The carbon atoms in martensite matrix are forced out from the lattice resulting in larger amount of SC. The average diameter of the carbide decreases by $15 \%$ after DCT.

Keywords: Martensitic stainless steel, Deep-cryogenic, Secondary carbide, EXAFS fitting

\section{INTRODUCTION}

The carbides in X90CrMoV18 martensitic stainless steel govern both hardness and fracture toughness, which are the key performance of tool steels. The $(\mathrm{Fe}, \mathrm{Cr})_{7} \mathrm{C}_{3}$ carbide is formed at higher carbon concentration contributing to the hardness value in steel. Fine precipitation of $(\mathrm{Fe}, \mathrm{Cr})_{23} \mathrm{C}_{6}$ improves the toughness. The size, shape, and distribution of carbides in steel are generally known to play an important role in mechanical properties. The $(\mathrm{Fe}, \mathrm{Cr})_{7} \mathrm{C}_{3}$ carbide, primary carbide, is normally found in the larger size and hexagonal shape while $(\mathrm{Fe}, \mathrm{Cr})_{23} \mathrm{C}_{6}$, secondary carbide, is usually found in smaller globular size [1-3]. The Deep-Cryogenic Treatment (DCT) processing is a modification of materials using cryogenic temperatures performed on products after conventional heat-treatment in order to increase their wear resistance in some materials. It is a refinement of secondary carbides attributed to the formation of secondary carbides, enhancement in its volume fraction, uniform distribution in the martensite matrix and transformations of Retained Austenite (RA). In additions, there two types of cryogenic treatment are usually applied as follows: (1) the sub-zero treatment is performed between -80 and $-140{ }^{\circ} \mathrm{C}$ after quenching. In this stage, the RA is reduced and higher wear resistance is obtained in tool steels; (2) the DCT is conducted at the temperatures below $-140{ }^{\circ} \mathrm{C}[4-5]$. In the current study, the effect of the carbide phase faction's ratio providing the optimum mechanical properties of $\mathrm{X} 90 \mathrm{CrMoV} 18$ steel is introduced in this research. The scratch testing is performed to quantify the fracture toughness $(\mathrm{Kc})$ of samples at the surface of the sample to the subsurface by $50 \mu \mathrm{m}$. This analytical framework based on linear elastic fracture mechanics. The scratch testing is well known in many applications including material characterization, including damage and wear of metals and polymers as well as the strength of 
materials. Moreover, the change in martensite lattice is investigated by the synchrotron Grazing Incident XRay Diffraction (GIXRD). The atomic fraction of the carbides in this research is investigated by synchrotron Xray Absorption Spectroscopy (XAS) technique. XAS is a useful technique to identify the atomic fraction of carbide dealing with selected chemical element to verify their quantity of materials. With the analysis XAS spectra, there are two spectra regions which are X-ray Absorption Near Edge Spectroscopy (XANES) and Extended X-ray Absorption Fine Structure (EXAFS). The shift in XANES energy could indicate changes in the microstructure since each element shows its own characteristic absorption edge. EXAFS is the results of the oscillation due to the scattering of X-ray from the neighbouring atoms. This is the fingerprint of each substance that can be used to identify unknown substances. Linear Combination Fit (LCF) method can calculate the phase fractions of the differences structure [6-7].

\section{EXPERIMENTAL METHOD}

The X90CrMoV18 steel type was used. Samples were prepared into coin-shape with $\varnothing 16.5 \mathrm{~mm} \times 2 \mathrm{~mm}$. Surface roughness was controlled in range 0.5-3.6 $\mu \mathrm{m} \mathrm{Rz}$. The steel studied in this investigation contained (in wt.\%) $0.83 \mathrm{C}, 17.6 \mathrm{Cr}, 1.01 \mathrm{Mo}$ and $0.07 \mathrm{~V}$. The samples were treated in different conditions as shown in Table 1. The hardness was measured using a micro-Vicker with a load of $1000 \mathrm{gf}$ (HV1). Using an image analyser, the carbide size of the X90CrMoV18 steel was obtained from image analysis of the average measurements of five randomly areas on sample surface for more than 1000 carbides. A scratch test is performed by drawing the Rockwell $\mathrm{C}$ conical probe stylus across the sample surface under a progressively increasing of vertical force. During the test, the tangency scratch forces (both vertical and horizontal) and the penetration depth are continuously measured as shown in Figure 1. In addition, fracture-induced acoustic waves are recorded by the embedded acoustic emission sensors [8-9].

Table 1 Thermal treatment conditions in this research

\begin{tabular}{|l|l|}
\hline Treating Conditions & Thermal treatment steps \\
\hline As quenched & Austenitized at $1050^{\circ} \mathrm{C}$ \\
\hline Sub-100 & Austenitized at $1050^{\circ} \mathrm{C}+$ Cryogenic Treatment $\left(-10{ }^{\circ} \mathrm{C}\right)(2 \mathrm{hr}$ soaking time $)$ \\
\hline Sub-140 & Austenitized at $1050^{\circ} \mathrm{C}+$ Cryogenic Treatment $\left(-140{ }^{\circ} \mathrm{C}\right)(2 \mathrm{hr}$ soaking time $)$ \\
\hline Deep-24 & Austenitized at $1050^{\circ} \mathrm{C}+$ Soaking in liquid nitrogen $24 \mathrm{hr}\left(-196{ }^{\circ} \mathrm{C}\right)$ \\
\hline Deep-48 & Austenitized at $1050^{\circ} \mathrm{C}+$ Soaking in liquid nitrogen $48 \mathrm{hr}\left(-196{ }^{\circ} \mathrm{C}\right)$ \\
\hline
\end{tabular}

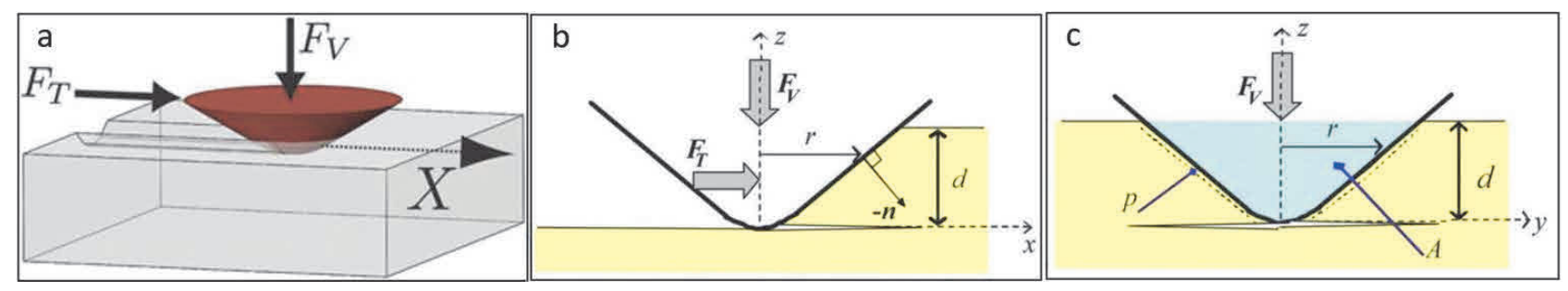

Figure 1 Schematic of a scratch test; (a) three-dimensional (3D) schematic of a scratch test. (b) Side view.

(c) Front view. Where: $x$ is the direction of the scratch. FT is the horizontal force, FV is the vertical force, and $\mathrm{d}$ is the depth of the scratch. $\mathrm{n}$ is the outward unit normal to the probe material interface, $A$ is the projected horizontal load bearing contact area, and $\mathrm{P}$ is the perimeter [10].

The GIXRD (see Figure 2) was used to study the change in martensite lattice. GIXRD was performed using $\mathrm{X}$-ray energy of $13 \mathrm{keV}$ for phase identification of species on the surface of samples. Scanning $2 \theta$ ranges performed between 10 to 70 degrees to cover the main diffraction peak of carbides. In details, the XRD pattern of (511), (420) and (422) diffraction peaks are represented the $\mathrm{Cr}_{23} \mathrm{C}_{6}$ carbide while the diffraction peaks (131), (211) and (132) is indicated the $\mathrm{Cr}_{7} \mathrm{C}_{3}$ phase. The synchrotron wavelength at $13 \mathrm{keV}$ is $1.0332 \AA$. The diffraction 
patterns were collected by 2D diffractometer. The XRD results were compared to the Powder Diffraction File (PDF) for phase identification of $(\mathrm{Fe}, \mathrm{Cr})_{7} \mathrm{C}_{3},(\mathrm{Fe}, \mathrm{Cr})_{23} \mathrm{C}_{6}$, and martensite lattice parameter. The incident angle between 1 and 3 degree was performed for studying variation of different phases in different depth profile.

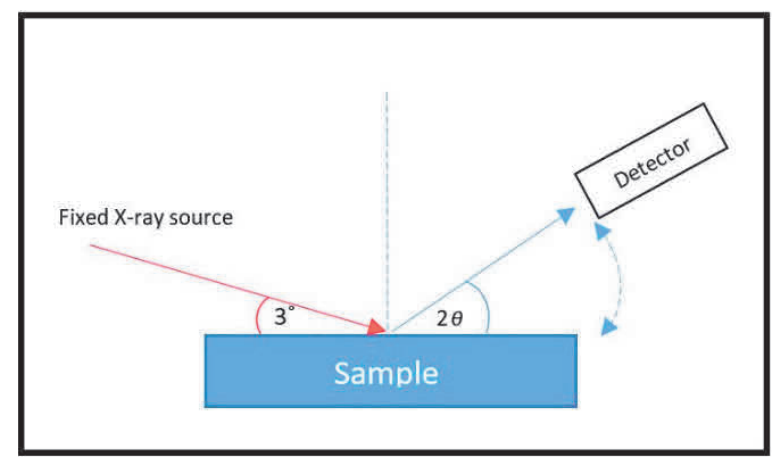

Figure 2 Schematic of GIXRD setup

Quantitative analysis of carbides was done by XAS analysis. XAS and GIXRD experiments were carried out at Siam Photon Laboratory (SPL) in the Synchrotron Light Research Institute (SLRI), Nakhon Rachasima, Thailand. All the EXAFS spectra and diffractions pattern were measured at beamline BL 1.1 W. The electron energy was $1.2 \mathrm{GeV}$. The chromium K-edge XAS spectra were recorded from metal samples in the X-ray fluorescence mode using a 13-elements germanium detector. The samples were set in a position where the angle between the sample surface, incident X-ray and the detector was 45 degree. The powder standard compounds of $\mathrm{Cr}_{7} \mathrm{C}_{3}$ and $\mathrm{Cr}_{23} \mathrm{C}_{6}$ were prepared in a thin layer film and measured in transmission mode. The scanning energy range was from - 150 to $15 \mathrm{keV}$ for chromium K-edge. Forth scans per sample were recorded to reduce the noise. The purity of $\mathrm{Cr}_{7} \mathrm{C}_{3}$ and $\mathrm{Cr}_{23} \mathrm{C}_{6}$ standard compounds for the XAS measurement was $99.5 \%$. The obtained spectra were processed in the Athena software for the background subtraction, data normalization, and LCF analysis. The LCF was carried out in the normalized spectra for quantifying the number of different forms of chromium carbide.

\section{RESULTS AND DISCUSSIONS}

The X-ray diffraction pattern indicated that the major phase of martensite matrix shifts after treating in cryogenic conditions as shown in Figure. 3. During DCT, the martensite matrix experiences contraction in the lattice. The Fe or substitutional atoms expansion and contraction result in the carbon atoms shift slightly out due to lattice deformation. This phenomenon makes c/a ratio of martensitic structure change resulting in lower carbons content in the matrix [11-12].

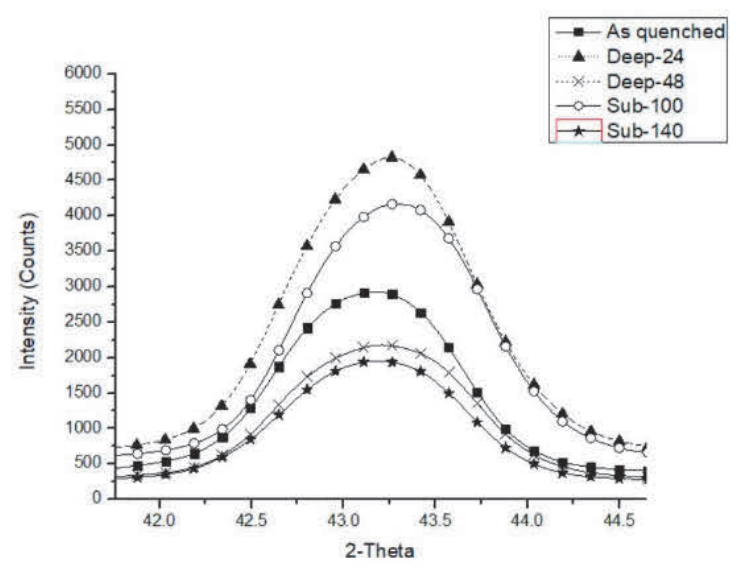

Figure $3 \mathrm{X}$-ray diffraction pattern of X90CrMoV18 in different treating conditions 
The ejected carbon atoms diffuse in the structure resulting in both carbides nucleation of $(\mathrm{Fe}, \mathrm{Cr})_{23} \mathrm{C}_{6}$ and growth in $(\mathrm{Fe}, \mathrm{Cr})_{7} \mathrm{C}_{3}$. After quenching, the coarse carbides dispersed in the matrix as illustrated in Figure 4(a). The DCT is a refinement of secondary carbides, enhancement in its volume fraction, and uniform distribution in the martensite matrix as shown in Figure 4.

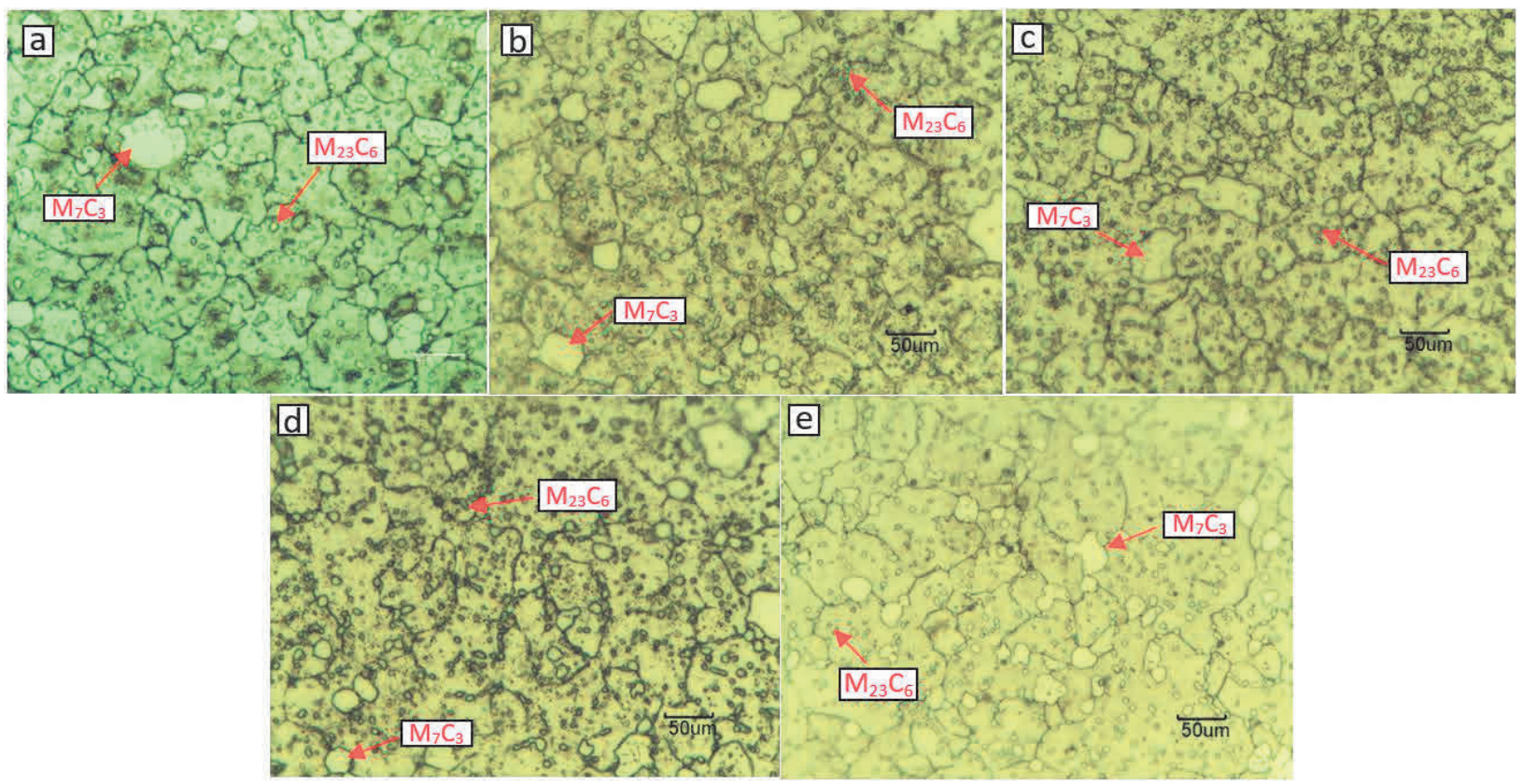

Figure 4 Microstructure of X90CrMoV18 in different treating conditions a) As quenched, b) Sub-100, c) Sub140, d) Deep-24 and e) Deep-48

The image analysis of the average size and amount of carbide varied according to the treatment condition can be seen in Figure 5. In Sub-100 and Sub-140, the average amount of carbide particles tends to decrease while the average volume fraction of carbide remains constant. The growth in $(\mathrm{Fe}, \mathrm{Cr})_{7} \mathrm{C}_{3}$ together with the nucleation of $(\mathrm{Fe}, \mathrm{Cr})_{23} \mathrm{C}_{6}$ can be observed by both image and XAS analysis. Then, the carbide particles of $(\mathrm{Fe}, \mathrm{Cr})_{23} \mathrm{C}_{6}$ gradually increase when the holding temperature and time are sufficient in Deep-24 and Deep-48 conditions.
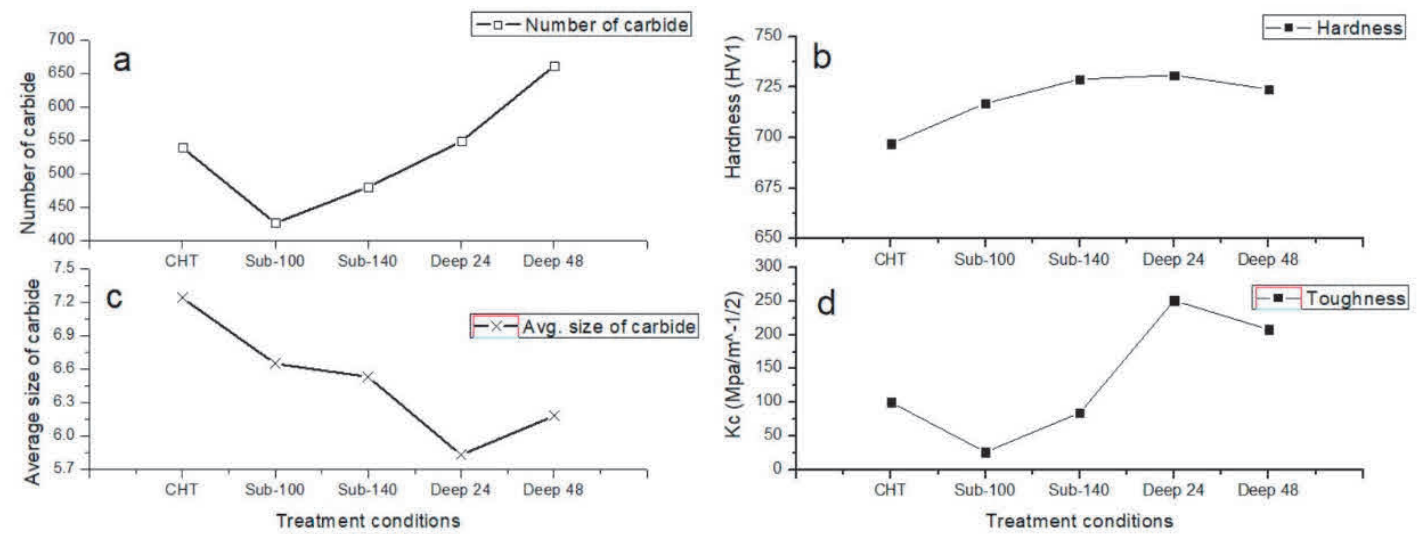

Figure 5 Mechanical properties and microstructural parameters measure in X90CrMoV18 steel

The nearest-neighbor distance between carbide is an important microstructural factor affecting $\mathrm{Kc}$, since the particle dimple is considered as the microvoids resulting in crack tip initiation and the distance as the crack propagation path. The relatively large carbide size makes the lower distance between a crack tip and cleavage 
initiation site resulting in lower $\mathrm{Kc}$ value. The refinement of $(\mathrm{Fe}, \mathrm{Cr})_{23} \mathrm{C}_{6}$ and uniform distribution are the major phenomena responsible for the improvement in properties of steel after DCT. The increasing of the distance between the carbide particles of such a matrix phase is resulting in higher fracture toughness, [13-15].

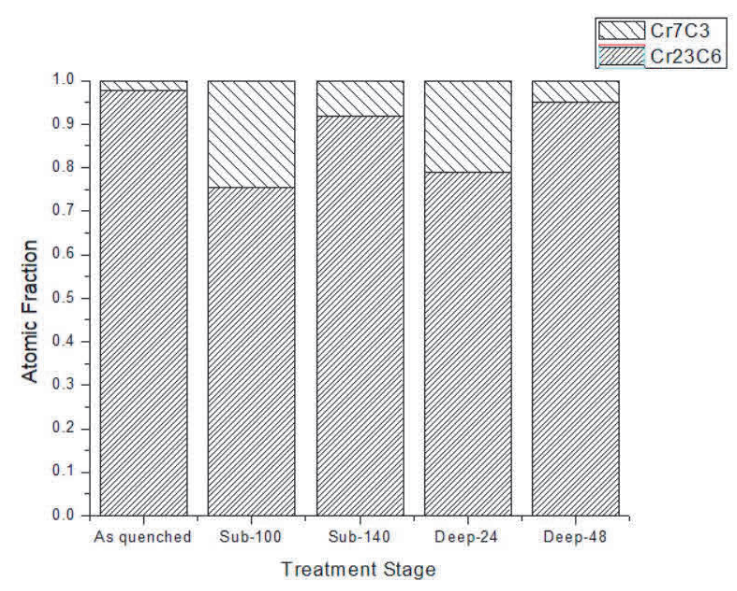

Figure 6 The atomic fraction of chromium carbides in form of $\mathrm{Cr}_{23} \mathrm{C}_{6}$ compared with the portion of that $\mathrm{Cr}_{7} \mathrm{C}_{3}$ under different treating conditions calculated by LCF

The phase fraction analysis between $(\mathrm{Fe}, \mathrm{Cr})_{23} \mathrm{C}_{6}$ and $(\mathrm{Fe}, \mathrm{Cr})_{7} \mathrm{C}_{3}$ has been confirmed by LCF. The details of the fitting results are demonstrated in Figure 6. Table 2 shows the summation deviating from 1.000 due to the standards. All the LCF results show a very low R-value confirming the high quality of fitting. The results have shown that the $(\mathrm{Fe}, \mathrm{Cr})_{23} \mathrm{C}_{6}$ dominates in all samples. In Sub-100 condition, the hard phase of $(\mathrm{Fe}, \mathrm{Cr})_{7} \mathrm{C}_{3}$ is predominated by the growing characteristic while the $(\mathrm{Fe}, \mathrm{Cr})_{23} \mathrm{C}_{6}$ is nucleated. This has been confirmed by the dramatically decreasing in $\mathrm{Kc}$ value. In Sub-140 condition, the nucleation of $(\mathrm{Fe}, \mathrm{Cr}){ }_{23} \mathrm{C}_{6}$ particles increases resulting in the decreasing in average carbides size while the carbide particles increase. In Deep- 24 condition, the effect of phase fraction's ratio has been proved by comparing between the As quenched and Deep-24 conditions. The Kc value improves dramatically after treating in Deep- 24 condition although the number of carbides of these samples is almost the same. The excessive fraction of $(\mathrm{Fe}, \mathrm{Cr})_{7} \mathrm{C}_{3}$ decreases the $\mathrm{Kc}$ value as can be seen in Sub-100 condition. The growth of $(\mathrm{Fe}, \mathrm{Cr}){ }_{23} \mathrm{C}_{6}$ can be observed in Deep-48 condition. The average size and amount of carbides increase in this stage.

Table 2 The atomic fraction of different precipitates calculated by the LCF and standard deviation the fraction

\begin{tabular}{|c|c|c|c|c|}
\hline & $\mathrm{Cr}_{7} \mathbf{C}_{3}$ & $\mathbf{C r}_{23} \mathbf{C}_{6}$ & Sum & R-value \\
\hline As quenched & $0.023( \pm 0.023)$ & $0.977( \pm 0.023)$ & 1.000 & 0.0044917 \\
\hline Sub-100 & $0.245( \pm 0.025)$ & $0.755( \pm 0.025)$ & 1.000 & 0.0053593 \\
\hline Sub-140 & $0.079( \pm 0.023)$ & $0.921( \pm 0.023)$ & 1.000 & 0.0046461 \\
\hline Deep-24 & $0.211( \pm 0.025)$ & $0.789( \pm 0.025)$ & 1.000 & 0.0055248 \\
\hline Deep-48 & $0.049( \pm 0.023)$ & $0.951( \pm 0.023)$ & 1.000 & 0.0046329 \\
\hline
\end{tabular}

\section{CONCLUSIONS}

This research indicates that the influence of the atomic phase fraction between $(\mathrm{Fe}, \mathrm{Cr})_{23} \mathrm{C}_{6}$ and $(\mathrm{Fe}, \mathrm{Cr})_{7} \mathrm{C}_{3}$ affect the $\mathrm{Kc}$ value of steels. The improvement of the $\mathrm{Kc}$ together with hardness can be done by taking the phases fraction between $(\mathrm{Fe}, \mathrm{Cr})_{23} \mathrm{C}_{6}$ and $(\mathrm{Fe}, \mathrm{Cr})_{7} \mathrm{C}_{3}$ into account. The excessive amount of $(\mathrm{Fe}, \mathrm{Cr})_{7} \mathrm{C}_{3}$ causes lower $\mathrm{Kc}$ value while it can be raised to $150 \%$ if it is controlled at the proper level. The Deep-24 condition provides excellent hardness and fracture toughness balance achieved with a $725 \mathrm{HV} 1$ and Kc values up to $250 \mathrm{MPa} \cdot \mathrm{m}^{1 / 2}$. This has been confirmed that the DCT change the c/a ratio of martensite investigated in GIXRD. 
The XAS proves that it is an efficient way to characterize the precipitation of chromium carbides. Although, the difficulties also can be found in the case of spectra extracting from various types of compounds in the samples. The relatively low carbides concentration in steels is very difficult to quantify by any other technique. The effect of carbon content on the c/a ratio of martensite will be analysed in future works. The appropriate ratio of these carbides will be proposed in the next publication. The growth mechanism of $(\mathrm{Fe}, \mathrm{Cr})_{7} \mathrm{C}_{3}$ and nucleation of $(\mathrm{Fe}, \mathrm{Cr})_{23} \mathrm{C}_{6}$ will be disclosed.

\section{ACKNOWLEDGEMENTS}

\section{The authors would like to thank for the financially supported by the Thailand Research Fund (TRF)} under contract No. PHD6010059.

\section{REFERENCES}

[1] WANG, J., ZUO, R.L. AND SUN, J.P. Influence of secondary carbides precipitation and transformation on hardening behavior of a $15 \mathrm{Cr}-1$ Mo-1.5 V white iron. Materials Characterization.2005. vol. 55, pp. 234-240.

[2] SITI HAWA, M. S. Investigation of Microstructures and Properties of 440C Martensitic Stainless Steel. International Journal of Mechanical and Materials Engineering. 2009, vol. 4, no. 2, pp. 21-24.

[3] AMINI, K., NEGAHBANI, M. AND GHAYOUR, H. The effect of deep cryogenic treatment on hardness and wear behavior of the $\mathrm{H} 13$ tool steel. La Metallurgia Italiana. 2015. Vol. 107, no. 3, pp. 53-58.

[4] JOSHI, P., SINGH, J. Effect of Cryogenic Treatment on Various Materials. A Review. HCTL. Open International Journal of Technology Innovations and Research (IJTIR). 2015. Vol. 14. DOI: 10.1080/10426914.2018.1424908

[5] SINGLA, A.K., SINGH, J. and SHARMA, V.S. Processing of materials at cryogenic temperature and its implications in manufacturing. A review, Materials and Manufacturing Processes. 2018. Vol. 14. DOI: 10.1080/10426914.2018.1424908

[6] TOCCI, M., LOSIO, M., SUWANPINIJ, P. and POLA, A. Experimental investigation on the formation of Crcontaining dispersoids in an AISi3 alloy by X-ray synchrotron radiation. Journal of Alloys and Compounds. 2018. vol. 742, pp. 555-562.

[7] WORABUT, A., THAMMAJAK, N., DICKERT, H. H. and SUWANPINIJ, P. Quantification of vanadium precipitates after reheating slab steel by synchrotron X-ray absorption spectroscopy (XAS). Key Engineering Materials. 2017, vol. 728, pp. 20-25.

[8] AKONO, A.T., ULM, F.J., REIS, P.M. and GERMAINE, J.T. Portable Scratch Testing Apparatus That Can Be Fixed on a Universal Testing Machine. Provisional Patent. Massachusetts Institute of Technology, 2013.

[9] AKONO, A.T., RANDALL, N.X. and ULM, F.J. Experimental Determination of The Fracture Toughness via Microscratch tests: Application to Polymers, Ceramics, and Metals. J. Mater. Res. 2017. vol. 27, pp. 485-493.

[10] AKONO, A.T. and ULM, F.J. Fracture Scaling for Scratch Tests of Axisymmetric Shape. J. Mech. Phys. Sol. 2012. vol. 60, pp. 379-390.

[11] Lu, Y., YU, H. and Sisson, R.D. Jr. The effect of carbon content on the c/a ratio of as-quenched martensite in FeC alloys. Materials Science and Engineering. 2017. vol. A 700, pp. 592-597.

[12] CHEARY, R.W. and MA-SORRELL, Y. Quantitative phase analysis by X-ray diffraction of martensite and austenite in strongly oriented orthodontic stainless steel wires. Journal of Mater. Sci. 2000. vol 35, pp. 11051113.

[13] LESKOVŠEK, W., ULE, B. and LIŠČI, B. Relations between fracture toughness, hardness and microstructure of vacuum heat-treated high-speed steel. Journal of Materials Processing Technology. 2002, vol. 127, pp. 298 - 308.

[14] HAHN, G.T. and ROSENFIELD, A.R. Sources of fracture toughness: the relation between KIc and the ordinary tensile properties of metals, applications related phenomena in titanium alloys. Am. Soc. Test. Mater. 1968. vol. 432, pp. 5-32.

[15] RICHARDS, N.L. and BARNBY, J.T. The Relationship Between Fracture Toughness and Microstructure in AlphaBeta Titanium Alloys. Mater. Sci. Eng. 1976. vol. 26, no. 2, pp. 221-229. 